\title{
Investigation of sheet bending parameters on springback in nickel coated mild steel sheets using response surface methodology
}

\author{
D. Pritima ${ }^{1, *}$ and P. Padmanabhan ${ }^{2}$ \\ ${ }^{1}$ Department of Mechanical Engineering, Vickram College of Engineering, Sivagangai 630561, Tamil Nadu, India \\ ${ }^{2}$ Department of Mechanical Engineering, V V College of Engineering, Tisaiyanvilai 627657, Tamil Nadu, India
}

Received: 8 December 2017 / Accepted: 22 January 2018

\begin{abstract}
Springback is the geometric change during forming process and it affects the dimensional accuracy of a finished product. This study aims to analyse the issue of springback in sheet bending by using response surface methodology (RSM). The effect of punch travel $(d)$, strain hardening index $(n)$, holding time $(t)$, punch velocity $(v)$ and width of the sheet $(w)$ on the springback was explained by contour plots. The experiments were designed as per Centre Composite design and also linear and quadratic polynomial equations were used for developing the mathematical model. The experimental results of the punch travel, velocity, width of the sheets increased which increases the springback. The holding time increases when the springback decreases. ANOVA analysis was used to identify the most significant factor which affects the springback and it indicates that the springback is inversely proportional to the holding time and the springback is directly proportional to the width of the sheets. The results of scanning electron microscope (SEM) and energy dispersive analysis of X rays analysis for the nickel coated mild steel were also reported.
\end{abstract}

Keywords: : Nickel coated mild steel / sheet bending / springback / RSM / ANOVA

\section{Introduction}

Metal forming process in the manufacture of various products like pipes, automobiles, house hold items, buildings, aesthetic items etc plays a significant role and nowadays, air bending process is the most widely used method in sheet metal shops because of its flexible characteristics. In recent years, clad sheet metals made up of different material components are widely used because of their exceptional mechanical and functional properties and are in high demand for the manufacturing of industrial products and the most important technical issue faced by the sheet metal forming industries was the prediction of springback [1]. In the manufacturing industries, steel sheets are extensively used and corrosion is a main factor which affects the surface of the sheets. So the demand for coating sheets got increased in order to protect the industrial product made of steel. The effect of heating current on the spring back of bended sample was developed and analyzed. The simulation was done to study the temperature variation with time, current in resistance heating and spring back [2]. The various factors considered for the determination of springback coefficient were radius of bending, size and nature of the sheet metal [3]. The

\footnotetext{
* e-mail: dpritima22@gmail.com
}

experimental and numerical investigation of laminated steel sheet in $V$-bending process considering non-linear visco-elasticity of polymer layer reported that the finite element model can be used to predict the final shape after bending and spring-back [4]. Bending is the most frequently process used during manufacturing of automotive safety parts which are achieved by consecutive sequences of blanking and bending in which the minimization of maximum punch load was achieved by the response surface methodology (RSM) based on design of experiments [5]. The release of residual stresses in the sheet metal results in springback and the prediction of springback in sheet forming simulation achieved only the smallest success in terms of solution accuracy. As a result RSM along with the finite element model was used as an optimization tool [6]. The experiment was carried out on HSS sheet and reported about the elimination of spring-back of high strength steel sheet by using additional bending with counter punch and the finite element simulation using an advanced kinematic hardening model [7].

The spring-back and spring-go behaviors in bending of thick plates of high strength steel at elevated temperature suggested a compensation method of the tool to improve the dimensional accuracy of the bend part [8]. The Bauschinger effect, transient behavior and permanent softening of dual phase steel sheet metal DP780 were 
studied and found the reasonable springback for three point bending tests through which the related hardening parameters are optimized [9]. Thickness of the sheet, tooling geometry, lubricating conditions, material properties and processing parameters were the important factors that affect the springback in bending process and developed the model for predicting springback with the help of artificial neural network approach [10]. The effect of thickness, $Y / E$ ratio, Poisson's ratio for non-linear work hardening material under pure bending determined the springback ratio using Ramberg-Osgood stress strain relationship with Tresca and Von-Mises yielding criteria [11]. The proposed novel model to predict the spring back in high strength and low alloy steel also proved that the hardening exponent, bending radius, thickness ratio, friction coefficient and blank holder force are the influential factors on the springback [12].

A RSM is a technique which has been proved more efficient than classical gradient based methods since it requires fewer iterations and convergence is guaranteed especially for non-linear problems. Naceur et al used RSM based on diffuse approximation which optimizes the tools geometry in sheet metal forming to reduce the springback effects after forming and also for the rapid design of aluminium sheet metal forming parameters $[13,14]$. The stress-strain relational behavior was considered during the determination of springback [15]. The mathematical and statistical techniques were used in RSM and this one was used to analyze the prediction of the response [16]. The micromechanical modeling of bending under forming behavior of dual phase steel 600 was achieved and concluded that the micro-macro modeling approach will enable the microstructure to be tailored for different applications in automobile industry [17]. The experimental investigations and statistical analysis of pulsed laser bending of AISI 304 stainless steel sheet were studied and they have considered laser power, scan speed, spot diameter and pulsed duration as input parameters and bending angle was considered as the output. They used RSM for modeling and optimization of the pulsed laser bending process [18]. The bending behavior was analyzed with empty and foam-filled beams using RSM and optimized the parameters [19]. The relationship between springback and various parameters like strain hardening exponent, coating thickness, die opening, die radius, punch radius, punch travel, and punch velocity were analyzed in air bending of electro galvanized steel sheet with the help of RSM and central composite design [20]. Draw bead design in sheet metal forming based on intelligent sampling was optimized using RSM [21]. Micro defcts were analyzed during the usage of sheet metal in deep drawing process [22]. The multiobjective robust optimization methodology to address the effects of parametric uncertainties on drawbead design used a dual response surface method to construct surrogate model and developed a multiobjective particle swarm optimization to generate robust Pareto solutions [23]. The various factors considered for different heat treatment conditions were punch radius, holding time and sheet thickness [24]. Thickness of sheet metal and grain size were the most influential factors for the determination of spring back [25].
The development of theoretical models for the sheet bending processes is complex because of its various control parameters. Springback prediction by the conventional method is more expensive and tedious. So this makes a way to develop a mathematical model using RSM. The mathematical model is developed with the help of regression analysis. The ANOVA test was carried out to find the significant factor and also to validate the experiment. The effect of die shoulder radius, punch-die clearance, punch nose radius and material properties on springback were investigated and also confirmed that the die corner radius has more influence on springback [26]. By varying the holding time and bend angles, corresponding springback values were recorded in $V$-bending test [27]. The effect of martensitic transformation on springback behavior was studied on 304L austenitic stainless steel [28]. The striking force was given to the work piece and was converted into desired three dimensional objects by using simple die [29].

The process of maintaining geometry accuracy in sheet bending is related with spring back. The response for spring back angle agrees well with experiments which also validates the developed model. The effect of the thickness ratio, normal anisotropy and the strain hardening exponent on the spring back angle were studied [30].

Nickel coated mild steel sheets are mainly used in batteries which gives better post corrosion resistance. $\mathrm{Ni}$ coated mild steel is used in control valves, cooling towers, steel compressors and also in food industries and nowadays they are in high demand. This work aimed to study the sheet bending behavior of nickel coated mild steel sheet using RSM. The intend of this cram was to establish the correlation among springback and the bending parameters, and to discover the process variables having significant persuade on the response. The effects of control parameters such as punch travel, strain hardening index, width of sheet, holding time, and punch velocity on springback were studied in detail.

\section{Experimental method}

\subsection{Electroplating process}

The work piece was fabricated through nickel electroplating method. It is a technique of electroplating a thin layer of nickel onto a mild steel. To achieve the better corrosion resistance, wear resistance and high strength, the nickel coating was applied on mild steel. Nickel electroplating is a process of depositing nickel on a mild steel. Before coating, mild steel sheet was involved in many primary processes such as cleaning, masking, pickling, and etching. Nickel plate is considered as anode and mild steel is considered as cathode terminal.

The $\mathrm{pH}$ level of the electrolyte was maintained in the range between 2.5 and 3 by adding $15 \%$ of dilute sulfuric acid and the range of temperature between $45^{\circ} \mathrm{C}$ and $50^{\circ} \mathrm{C}$. Nickel was deposited on the mild steel by electroplating process. In this method, low reaction temperature was occurred during electroplating process which is kept stress free process. The deposition parameters were easily controlled and manipulated by this process. The quality 
Table 1. Experimental layout and results for the springback.

\begin{tabular}{|c|c|c|c|c|c|c|}
\hline S.No & $\begin{array}{c}\text { Punch } \\
\text { travel }(\mathrm{mm}) \\
\end{array}$ & $\begin{array}{c}\text { Strain hardening } \\
\text { index }\end{array}$ & $\begin{array}{c}\text { Holding } \\
\text { time (min) }\end{array}$ & $\begin{array}{c}\text { Punch velocity } \\
(\mathrm{mm} / \mathrm{s})\end{array}$ & $\begin{array}{l}\text { Width of the } \\
\text { sheet }(\mathrm{mm})\end{array}$ & $\begin{array}{c}\text { Spring back } \\
\text { (degrees) }\end{array}$ \\
\hline 1 & 10 & 0.22 & 2.5 & 0.666 & 40 & 3.7 \\
\hline 2 & 15 & 0.27 & 5 & 0.499 & 70 & 1.7 \\
\hline 3 & 15 & 0.27 & 5 & 0.166 & 50 & 3.1 \\
\hline 4 & 20 & 0.24 & 2.5 & 0.666 & 40 & 2.4 \\
\hline 5 & 15 & 0.27 & 0 & 0.499 & 50 & 0.8 \\
\hline 6 & 15 & 0.27 & 5 & 0.499 & 50 & 1.4 \\
\hline 7 & 15 & 0.27 & 5 & 0.499 & 50 & 2.2 \\
\hline 8 & 10 & 0.22 & 7.5 & 0.333 & 40 & 1.9 \\
\hline 9 & 15 & 0.27 & 5 & 0.499 & 50 & 2.3 \\
\hline 10 & 15 & 0.27 & 5 & 0.499 & 50 & 2.4 \\
\hline 11 & 10 & 0.24 & 7.5 & 0.666 & 40 & 3.2 \\
\hline 12 & 20 & 0.22 & 2.5 & 0.666 & 60 & 3.2 \\
\hline 13 & 10 & 0.22 & 7.5 & 0.666 & 60 & 1.6 \\
\hline 14 & 20 & 0.22 & 7.5 & 0.333 & 60 & 0.8 \\
\hline 15 & 20 & 0.22 & 7.5 & 0.666 & 40 & 2.2 \\
\hline 16 & 20 & 0.24 & 7.5 & 0.333 & 40 & 2.6 \\
\hline 17 & 10 & 0.24 & 2.5 & 0.333 & 40 & 3.5 \\
\hline 18 & 15 & 0.23 & 5 & 0.499 & 50 & 2.5 \\
\hline 19 & 20 & 0.24 & 7.5 & 0.666 & 60 & 1.7 \\
\hline 20 & 15 & 0.27 & 5 & 0.499 & 30 & 4.2 \\
\hline 21 & 20 & 0.22 & 2.5 & 0.333 & 40 & 2.8 \\
\hline 22 & 10 & 0.24 & 7.5 & 0.333 & 60 & 3.3 \\
\hline 23 & 15 & 0.27 & 5 & 0.499 & 50 & 3.5 \\
\hline 24 & 15 & 0.21 & 5 & 0.499 & 50 & 2.5 \\
\hline 25 & 15 & 0.27 & 5 & 0.833 & 50 & 1.7 \\
\hline 26 & 15 & 0.27 & 5 & 0.499 & 50 & 2.7 \\
\hline 27 & 5 & 0.27 & 5 & 0.499 & 50 & 4 \\
\hline 28 & 20 & 0.24 & 2.5 & 0.333 & 60 & 2.1 \\
\hline 29 & 15 & 0.27 & 10 & 0.499 & 50 & 2.8 \\
\hline 30 & 10 & 0.24 & 2.5 & 0.666 & 60 & 1.9 \\
\hline 31 & 25 & 0.27 & 5 & 0.499 & 50 & 3.2 \\
\hline 32 & 10 & 0.22 & 2.5 & 0.333 & 60 & 3.6 \\
\hline
\end{tabular}

of electroplated nickel mainly depends on the coating thickness, holding time and uniformity of the deposited metal. The nickel anode was dissolved into the electrolyte in the form of nickel ions. The ions travel through the solution and deposited on the cathode.

\subsection{Experimental details}

The dimensions of the sheet used for the present study are, (i) $120 \times 30 \times 0.68 \mathrm{~mm}$, (ii) $120 \mathrm{~mm} \times 40 \mathrm{~mm} \times 0.68 \mathrm{~mm}$, (iii) $120 \mathrm{~mm} \times 50 \mathrm{~mm} \times 0.68 \mathrm{~mm}$, (iv) $120 \mathrm{~mm} \times 60 \mathrm{~mm}$ $\times 0.68 \mathrm{~mm}$ and (v) $120 \mathrm{~mm} \times 70 \mathrm{~mm} \times 0.68 \mathrm{~mm}$. The scanning electron microscope (SEM) analysis was carried out for the nickel coated mild steel sheets using SEMZEISS machine. The composition of the casted materials was verified by energy dispersive analysis of $\mathrm{X}$ rays (EDAX) analysis. The sheet bending operation was performed as per the design matrix and the measured output parameter (springback) was provided in Table 1. The five independent controlled input parameters are chosen as $A$ : punh travel, $B$ : strain hardening index, $C$ : holding time, $D$ : punch velocity and $E$ : width of the sheet in which they have great effect on springback.

\section{Results and discussion}

\subsection{SEM and EDAX analysis of nickel coated mild steel sheets}

The morphology of the nickel coated mild steel sheets is presented in Figure 1. This image Figure 1a shows that the nickel was appropriately coated on the surface of the mild steel sheets and the $\mathrm{Ni}$ was well dissolved in the surface of the mild steel sheet. Figure 1b shows the morphology of Ni 

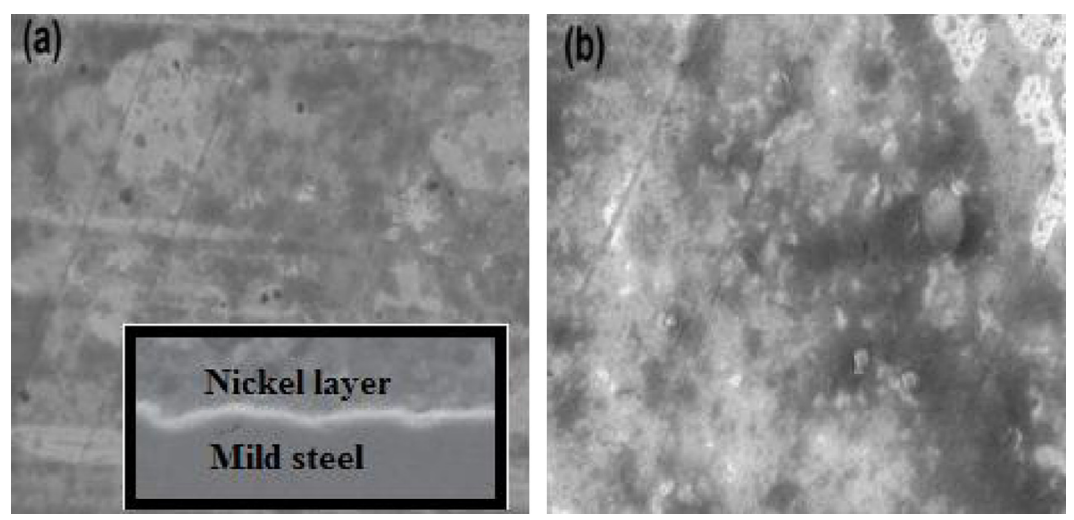

Fig. 1. SEM images of nickel coated mild steel sheets.
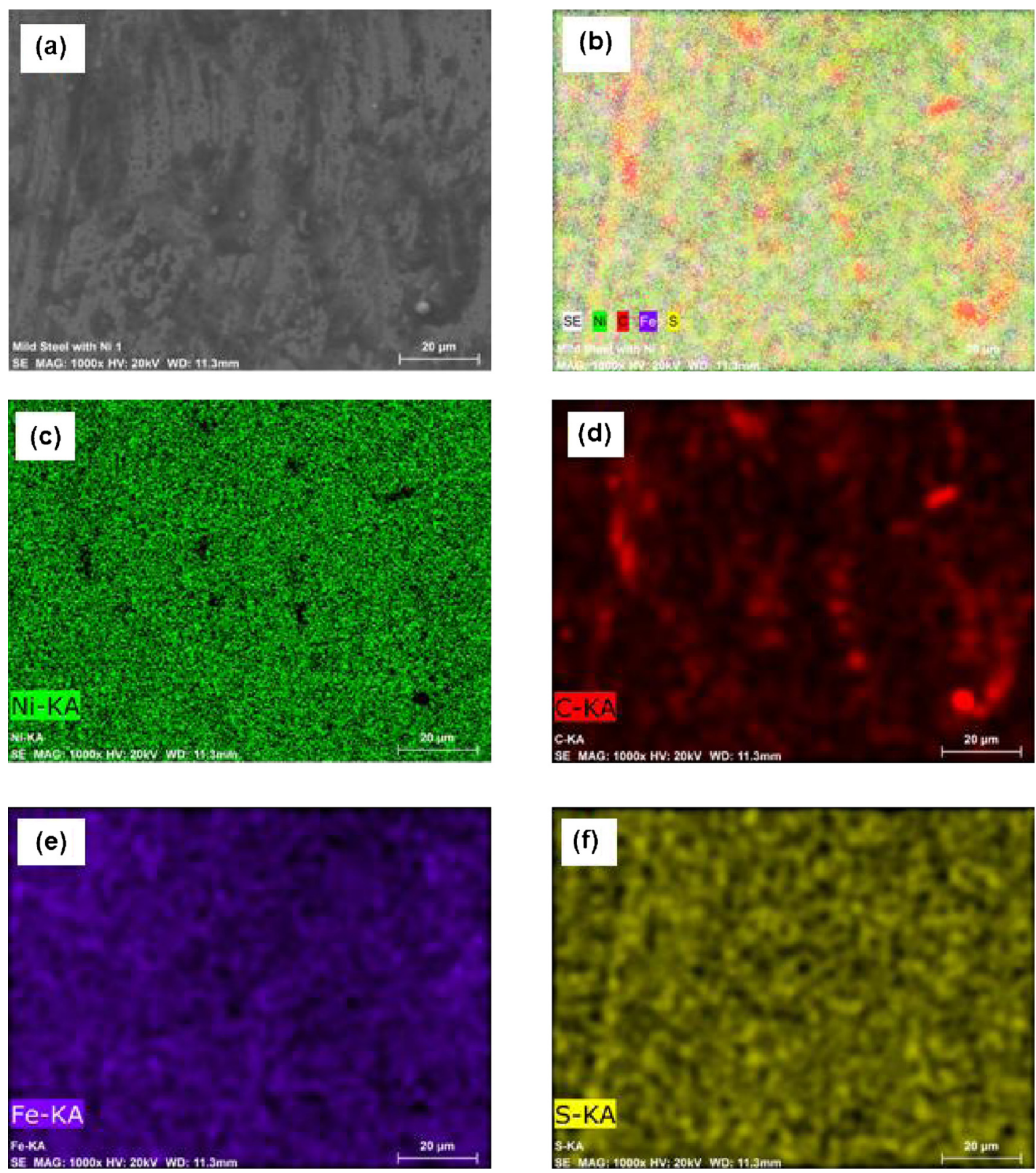

Fig. 2. (a-f) EDAX analysis of nickel coated mild steel sheets. 
Table 2. Analysis of variance results for springback.

\begin{tabular}{|c|c|c|c|c|}
\hline Source & Adj SS & Adj MS & $F$-value & $P$-value \\
\hline Model & 23.9430 & 1.19715 & 8.57 & 0.000 \\
\hline Linear & 12.4283 & 2.48566 & 17.79 & 0.000 \\
\hline $\mathrm{A}=$ punch travel & 4.1611 & 4.16105 & 29.78 & 0.000 \\
\hline $\mathrm{B}=$ strain hardening index & 5.3875 & 5.38751 & 38.56 & 0.000 \\
\hline $\mathrm{C}=$ holding time & 0.0403 & 0.04033 & 0.29 & 0.602 \\
\hline $\mathrm{D}=$ punch velocity & 1.3727 & 1.37267 & 9.82 & 0.010 \\
\hline $\mathrm{E}=$ width of the sheet & 0.8078 & 0.80775 & 5.78 & 0.035 \\
\hline Square & 3.4754 & 0.69508 & 4.97 & 0.013 \\
\hline $\mathrm{A} \times \mathrm{A}$ & 0.2007 & 0.20074 & 1.44 & 0.256 \\
\hline $\mathrm{B} \times \mathrm{B}$ & 1.1672 & 1.16717 & 8.35 & 0.015 \\
\hline $\mathrm{C} \times \mathrm{C}$ & 0.1458 & 0.14583 & 1.04 & 0.329 \\
\hline $\mathrm{D} \times \mathrm{D}$ & 0.1986 & 0.19863 & 1.42 & 0.258 \\
\hline $\mathrm{E} \times \mathrm{E}$ & 1.1806 & 1.18056 & 8.45 & 0.014 \\
\hline 2-Way & 10.8360 & 1.08360 & 7.75 & 0.001 \\
\hline $\mathrm{A} \times \mathrm{B}$ & 0.3254 & 0.32536 & 2.33 & 0.155 \\
\hline $\mathrm{A} \times \mathrm{C}$ & 0.0006 & 0.00059 & 0.00 & 0.949 \\
\hline$A \times D$ & 0.4402 & 0.44019 & 3.15 & 0.104 \\
\hline $\mathrm{A} \times \mathrm{E}$ & 0.0870 & 0.08701 & 0.62 & 0.447 \\
\hline $\mathrm{B} \times \mathrm{C}$ & 1.2764 & 1.27642 & 9.13 & 0.012 \\
\hline $\mathrm{B} \times \mathrm{D}$ & 3.7141 & 3.71405 & 26.58 & 0.000 \\
\hline $\mathrm{B} \times \mathrm{E}$ & 1.9907 & 1.99074 & 14.25 & 0.003 \\
\hline $\mathrm{C} \times \mathrm{D}$ & 0.0028 & 0.00279 & 0.02 & 0.890 \\
\hline $\mathrm{C} \times \mathrm{E}$ & 3.0899 & 3.08989 & 22.11 & 0.001 \\
\hline $\mathrm{D} \times \mathrm{E}$ & 0.0321 & 0.03213 & 0.23 & 0.641 \\
\hline Error & 1.5370 & 0.13973 & - & - \\
\hline Lack-of-fit & 0.4370 & 0.07284 & 0.33 & 0.895 \\
\hline Pure error & 1.1000 & 0.22000 & - & - \\
\hline Total & 25.4800 & - & - & - \\
\hline
\end{tabular}

coated mild steel at higher magnification at $200 \mathrm{~nm}$ scale. It was studied that the nano level Ni particles are arranged on the surface of the mild steel which gives the impression that this coating was perfectly done. The coating thickness and layers were exemplified by SEM through cross sectional view as shown in Figure 1a. The coating thickness variation was directly proportional to the electrode gaps and plating time. The large electrode gap results in more amount of coating as well as uniform layers. The coating layers consist of black and bright nickel which was visible in Figure 1b. The bright nickel has larger grains when compared to the black nickel. The low grain size decreases the bonding strength of the coatings whereas the larger grain size increases the adhesive strength of the coatings and have excellent thermal constancy. The SEM image Figure 1b confirmed that the enormous bright nickel grains were obtained during coating process.

Figure $2 \mathrm{a}-\mathrm{f}$ shows the results of EDAX analysis of $\mathrm{Ni}$ coated mild steel sheets. This analysis was conducted to evidence the presence of appropriate elements in mild steel as well as the coated $\mathrm{Ni}$ element. Figure $2 \mathrm{~b}$, shows the required composition of the mild steel along with $\mathrm{Ni}$ coating. Figure 2(c-f) ensures the presence of elements such as $\mathrm{Ni}, \mathrm{C}, \mathrm{Fe}$ and $\mathrm{S}$ respectively. Also the presence of nickel in high intensity ensures that the surface is appropriately coated by Ni. The presence of nickel is confirmed by the EDAX mapping shown in the Figure 2c which have large grain size and excellent adhesive properties.

\subsection{Hardness and surface roughness test}

The experiments were carried out with 2 sets of specimen, one based on mild steel and an other based on nickel coated mild steel sheet. The Rockwell hardness of the specimens is calculated with respect to different sheets. Diamond indentor with $150 \mathrm{kgf}$ load was applied during hardness test. The hardness of the plain mild steel was found to be $65 \mathrm{HV}$. The hardness for the nickel coated MS specimen was increased to $85 \mathrm{HV}$. This indicates that the nickel coating increases the hardness of the substrate at surface level. The roughness test was carried out for plain mild steel (uncoated) and nickel coated mild steel specimens. It was also found that uncoated mild steel specimens have large variation in roughness $(1.66 \mu \mathrm{m})$ when compared to nickel 
Table 3. Confirmation test.

\begin{tabular}{|c|c|c|c|c|c|c|c|c|}
\hline S.No & $\begin{array}{c}\text { Punch } \\
\text { travel (mm) }\end{array}$ & $\begin{array}{c}\text { Strain } \\
\text { hardening } \\
\text { index }\end{array}$ & $\begin{array}{l}\text { Holding } \\
\text { time (min) }\end{array}$ & $\begin{array}{c}\text { Punch } \\
\text { velocity } \\
(\mathrm{mm} / \mathrm{s})\end{array}$ & $\begin{array}{l}\text { Width of the } \\
\text { sheet }(\mathrm{mm})\end{array}$ & $\begin{array}{l}\text { Springback degree } \\
\text { experimental value }\end{array}$ & $\begin{array}{l}\text { Springback degree } \\
\text { predicted value }\end{array}$ & Error \% \\
\hline 1 & 10 & 0.22 & 2.5 & 0.666 & 40 & 3.7 & 4.125 & 11.4 \\
\hline 2 & 15 & 0.27 & 5 & 0.499 & 70 & 1.7 & 1.95 & 14 \\
\hline
\end{tabular}

coated specimens $(0.624 \mu \mathrm{m})$. Hence, it may be concluded that coated process can improve the surface quality of the substrate.

\subsection{Determination of springback}

The experiment was done in Universal Testing Machine (UTM) in which hardened steel is used as die and punch. The sample work piece is carefully placed in suitable position on the die and the load was gradually applied on the work piece. Finally the required springback angle was determined by the difference between the bend angles before and after deformation as shown in Table 1. This experiment was repeated for various levels.

\subsection{Development of the empirical relationship and ANOVA analysis}

In this investigation, the central composite face centered design was used, which fits the second order response surface very accurately. All coefficients were obtained by applying central composite face centered design. After determining the significant coefficients, the final relationship was developed using only those coefficients. The final empirical relationship to predict springback of nickel coated mild steel sheet is given below in equation (1). The developed model was used to predict the output response such as spring back.

$$
\begin{aligned}
\text { Springback } & =58.6+0.501 A-442 B-3.65 C \\
& -31.92 D+0.523 E-0.00351 A \\
& * A+837 B * B+0.0297 C * C+3.14 D \\
& * D-0.002127 E * E-1.227 A * B \\
& -0.00053 A * C-0.236 A * D \\
& -0.00162 A * E+10.10 B * C+133.5 B \\
& * D-1.518 B * E+0.038 C \\
& * D+0.01927 C * E-0.0319 D * E .
\end{aligned}
$$

As for ANOVA technique, if the calculated value of the $F$ ratio of the developed model was less than the standard $F$ ratio value at a desired level of confidence (95\%), then the model was said to be adequate within the confidence limit. ANOVA test results are presented in Table 3 for the model. From the table, it was understood that the developed relationship is found to be adequate at $95 \%$ confidence level. Values of "Prob $>F$ " less than 0.0500 indicate that model terms are significant. In this case, $B^{2}$ are significant model terms. Values greater than 0.1000 indicate that the model terms are not significant. The results of ANOVA for springback are shown in Table 2 .

\subsection{Analysis of contour plots}

Contour plots also called level plots are used to represent the three dimensional surface on a two dimensional plane. Contour plots are drawn to show the effectiveness of the applied method and a suitable design region was readily identified [31]. These plots gave a clear picture about interactions between the process parameters and response.

The above Figure 3a shows that the springback was minimum for the high value of punch travel and strain hardening index. The maximum springback was obtained at the combination of $15 \mathrm{~mm}$ punch travel and 0.21 of strain hardening index. The desirable springback is achieved when the punch travel is above $15 \mathrm{~mm}$ and also when the strain hardening index was above 0.24.

In Figure 3b, the springback was minimum at the high value of punch travel and holding time of $5 \mathrm{~min}$. The maximum value of springback was obtained at the lower values of punch travel and holding time of $5 \mathrm{~min}$. There was no significant effect of holding time on springback. The values of springback decrease linearly for the values of punch travel greater than $20 \mathrm{~mm}$ and holding time above $3 \mathrm{~min}$.

It is observed from Figure $3 \mathrm{c}$ that most of the contour plot was occupied by high springback. At the combination of $25 \mathrm{~mm}$ punch travel and $0.5 \mathrm{~mm} / \mathrm{sec}$ punch velocity, the springback was minimum.

It is very clear from Figure $3 d$ that the springback value was minimum at the punch travel of $15 \mathrm{~mm}$ and width of the sheet of $70 \mathrm{~mm}$. The minimum springback was also obtained at the punch travel of $25 \mathrm{~mm}$ and width of the sheet of $50 \mathrm{~mm}$. Width of the sheet should be more than $50 \mathrm{~mm}$ to obtain the minimum springback.

In Figure 3e, the springback was minimum at the high value of strain hardening index and lower value of holding time. The maximum springback was obtained at the minimum value of strain hardening index and holding time of $5 \mathrm{~min}$.

In Figure 3f, the springback value decreases linearly. Maximum springback was achieved at both the higher values of strain hardening index and width of the sheet.

In Figure 3g, the springback value was minimum at the combination of strain hardening index (0.24) and punch velocity of $0.5 \mathrm{~mm} / \mathrm{s}$. The strain hardening index and punch velocity have much lesser influence on desired springback.

In Figure 3h, the minimum springback was obtained at the combination of higher value of width of the sheet and the punch velocity from 0.4 to $0.6 \mathrm{~mm} / \mathrm{s}$

The normal probability plots of the springback are shown in Figure 4 and it is clearly noticed that all the values of springback fall on a straight line showing the normal distribution [32]. 


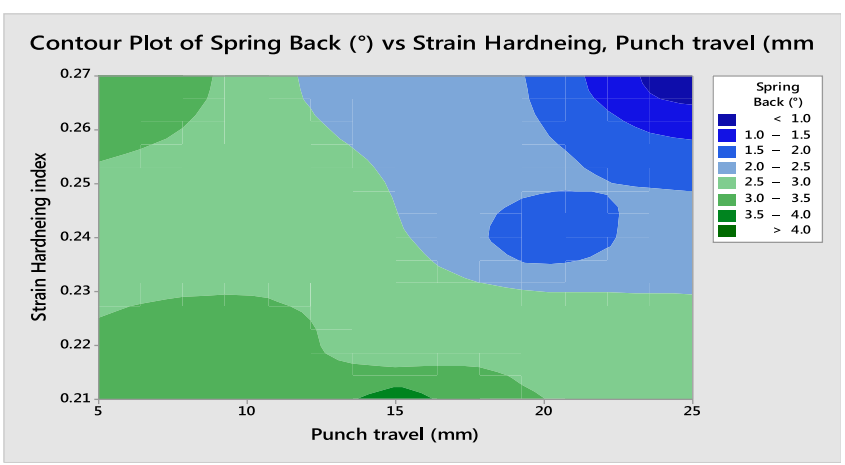

(a)

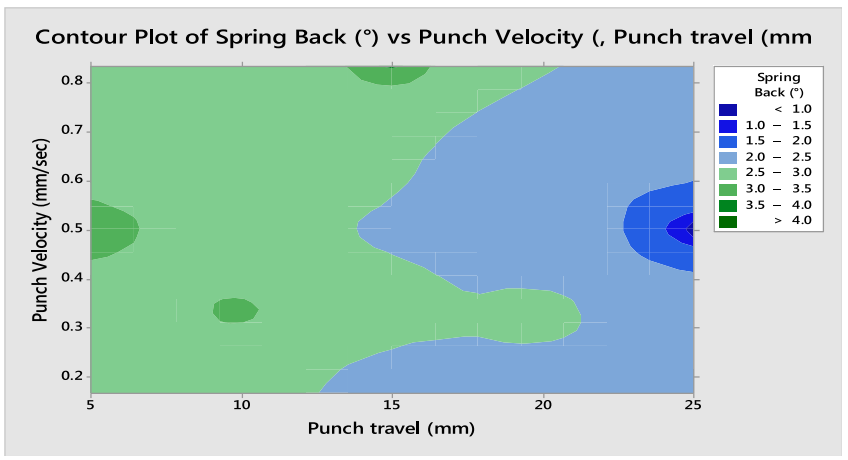

(c)

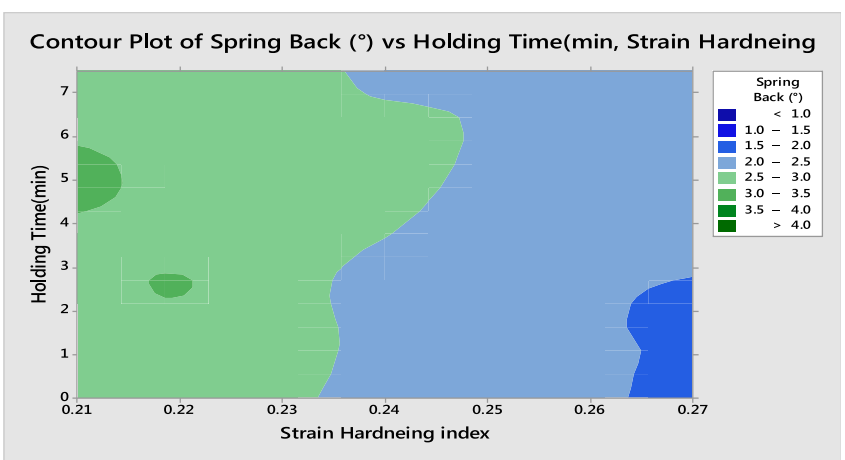

(e)

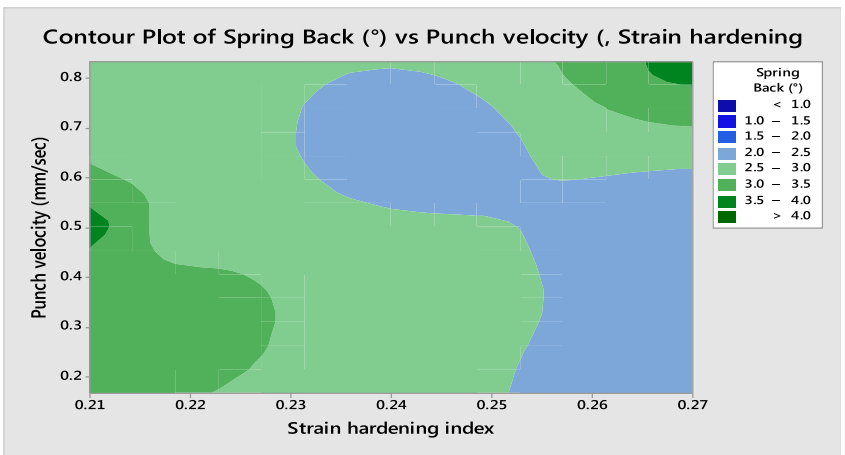

(g)

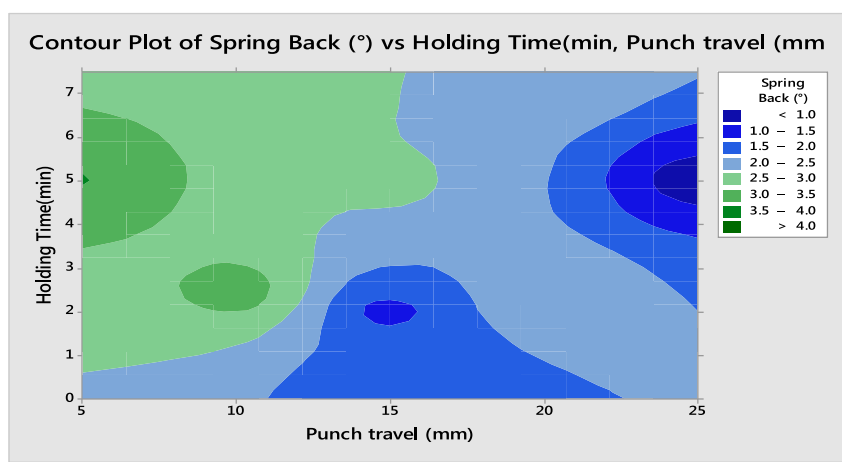

(b)

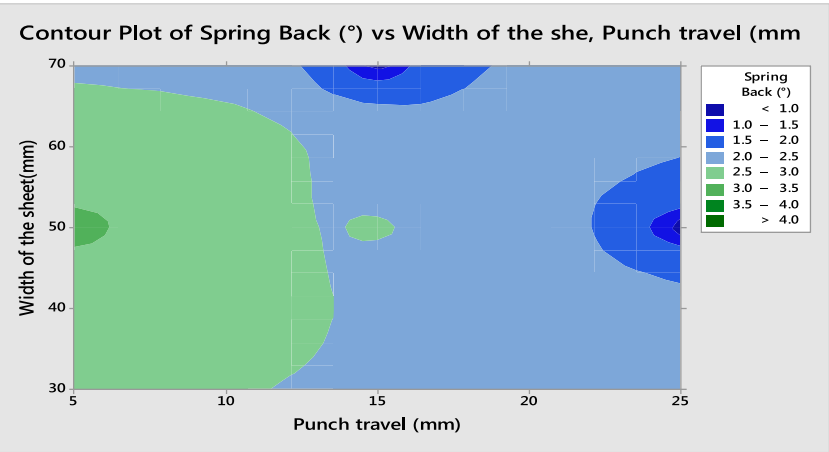

(d)

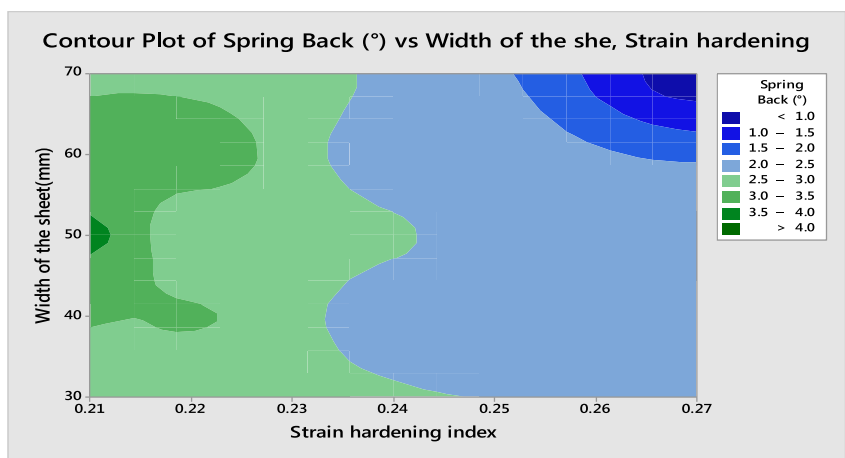

(f)

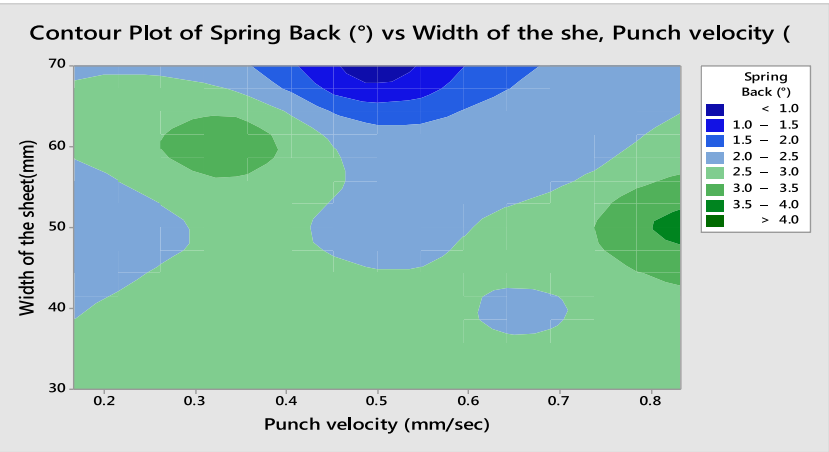

(h)

Fig. 3. (a) Contour plot: punch travel vs. strain hardening index, (b) contour plot: punch travel vs. holding time, (c) contour plot: punch travel vs. punch velocity, (d) contour plot: punch travel vs. width of the sheet, (e) contour plot: strain hardening index vs. holding time, (f) contour plot: strain hardening index vs. width of the sheet, (g) contour plot: strain hardening index vs. punch velocity, (h) contour plot: punch velocity vs. width of the sheet. 


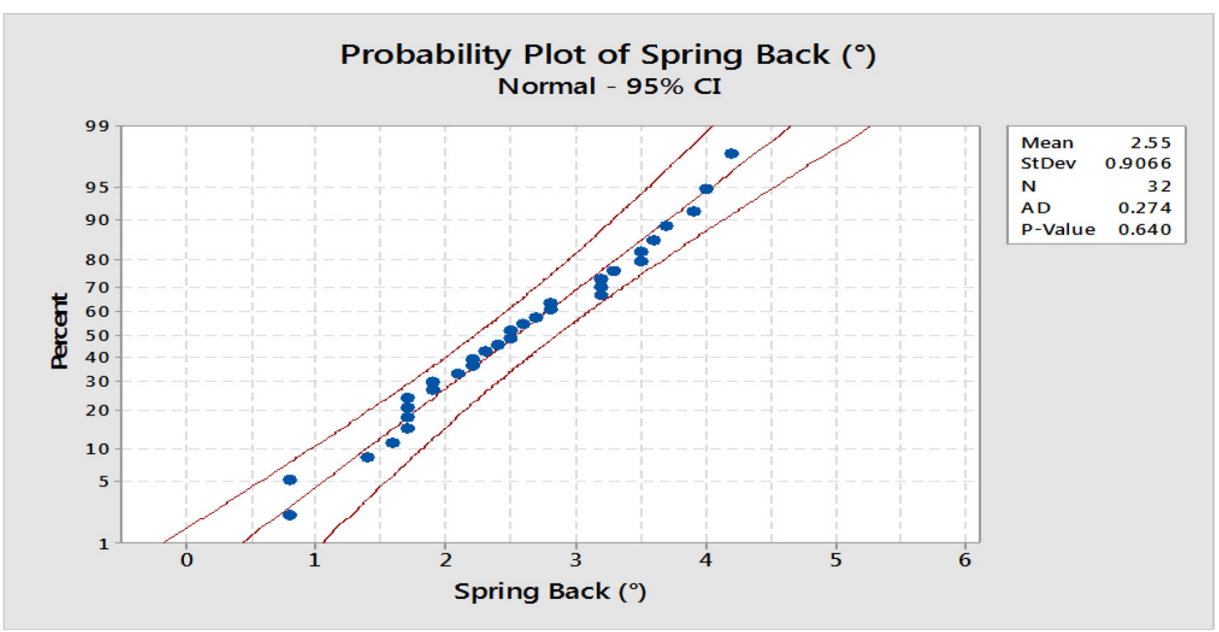

Fig. 4. Normal probability plot of springback.

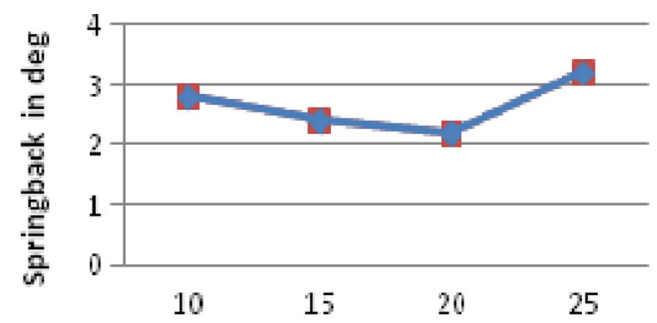

(a)
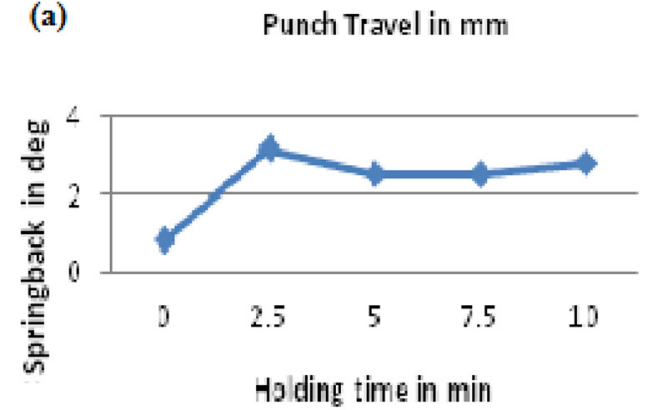

(c)
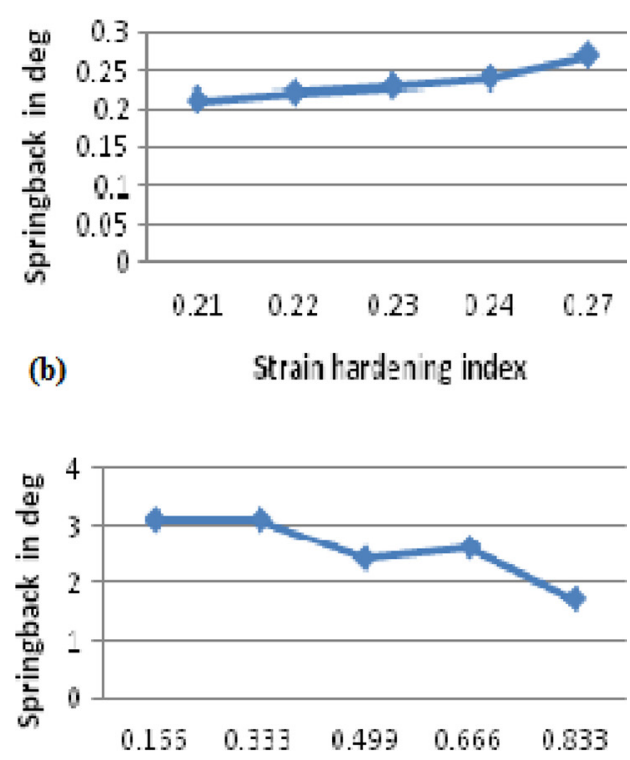

(d) Punch Velcaty in $\mathrm{mm} / \mathrm{sec}$

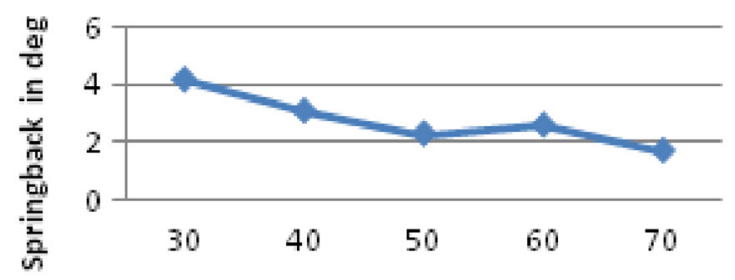

(e)

Width of the sheet in $\mathrm{mm}$

Fig. 5. (a-e) Effect of process parameters on springback.

\subsection{Effect of process parameters on springback}

This section deals with the direct effect of the individual parameter on springback. The direct effects of the design parameters are illustrated in Figure 5a-e. Figure 5a shows that springback increases for increasing punch travel. This was due to the fact that the bending moment was proportional to the springback angle. Figure 5b illustrates that the increase in strain hardening index increases the value of springback which is because of increasing 
resistance in plastic yielding [26]. Figure 5c shows that the springback remains constant in all the values of holding time. The effect of punch velocity on springback is shown in Figure 5d and it shows that springback decreases for increasing values of punch velocity. The influence of width of the sheet on springback is shown in Figure 5e and it is evident that springback also decreases for increasing values of width of sheet.

\subsection{Confirmation test for the experiments}

The prediction results of the RSM model were tested by performing confirmation experiments for the various values of the process parameters which are compared with the results of prediction model. Table 3 clearly shows the comparison between the experimental and predicted values in which the error is calculated as

$$
\operatorname{Error}(\%) \equiv\left|\left(\frac{(Y p-Y \exp )}{Y \exp }\right)\right| \times 100,
$$

where, $Y p$ is the predicted value and $Y \exp$ is the experimental value. It is found that the error percentage calculated is small and so the developed model is found to be accurate.

\section{Conclusions}

The following conclusions are drawn from the above study: - sheet bending behavior of nickel coated mild steel was analyzed for the springback by using RSM;

- strain hardening index is the most influencing factor on springback followed by punch travel;

- an empirical relationship was developed to predict the springback of sheet bending of nickel coated mild steel sheets during bending using RSM;

- the mathematical model developed is in close agreement with experiment results. The confirmation experiment shows that percentage of error between measured value and predicted value is small;

- SEM analysis revealed the morphology of the nickel coated mild steel sheets and EDAX results confirm the evidence of the presence of nickel and some elements including iron, sulphur, etc;

- it was noticed that smaller punch travel produces higher springback.

The developed relationship can be effectively used to predict the springback of sheet bending at $95 \%$ confidence level.

\section{References}

[1] K. Yilamu, R. Hino, H. Hamasaki, F. Yoshida, Air bending and springback of stainless steel clad aluminum sheet, J. Mater. Process. Technol. 210 (2010) 272-278

[2] D. Nie, Z. Lu, K. Zhang, Hot bending behavior of SUS 304 stainless steel sheet assisted by resistance heating: multi-field coupling numerical simulation and experimental investigation, Int. J. Adv. Manuf. Tech. 87 (2016) 2763-2774
[3] H.L. Dai, H.J. Jiang, T. Dai, W.L. Xu, A.H. Luo, Investigation on the influence of damage to springback of U-shape HSLA steel plates, J. Alloys Compd. 708 (2017) 575-586

[4] H. Li, J. Chen, J. Yang, Experimental and numerical investigation of laminated steel sheet in $V$-bending process considering non-linear visco-elasticity of polymer layer, J. Mater. Process. Technol. 212 (2012) 36-45

[5] R. Bahloul, A. Mkaddem, D. Santo, Sheet metal bending optimisation using response surface method, numerical simulation and design of experiments, Int. J. Mech. Sci. 48 (2006) 991-1003

[6] P.A. Eggertsen, K. Mattiasson, The modelling of the bending-unbending behaviour for accurate springback predictions, Int. J. Mech. Sci. 51 (2009) 547-563

[7] L. Komgrit, H. Hamasaki, R. Hino, F. Yoshida, Elimination of springback of high-strength steel sheet by using additional bending with counter punch, J. Mater. Process. Technol. 229 (2016) 199-206

[8] J. Lee, K. Lee, D. Kim, H. Choi, B. Kim, Spring-back and spring-go behaviors in bending of thick plates of highstrength steel at elevated temperature, Comput. Mater. Sci. 100 (2015) 76-79

[9] S. Zang, M. Gyu, L.L. Sun, J.H. Kim, Measurement of the Bauschinger behavior of sheet metals by three-point bending springback test with pre-strained strips, Int. J. Plast. 59 (2014) 84-107

[10] R. Kazan, M. Firat, A.E. Tiryaki, Prediction of springback in wipe-bending process of sheet metal using neural network, Mater. Des. 30 (2009) 418-423

[11] R.K. Lal, J.P. Dwivedi, V.P. Singh, Springback analysis in sheet metal forming of non-linear work-hardening material under pure bending J. Inst. Eng. (India) 98 (2017) 155-170

[12] H.J. Jiang, H. Liang, Novel model to predict U-bending springback and time-dependent springback for a HSLA steel plate, Int. J. Adv. Manuf. Tech. 81 (2015) 1055-1066

[13] H. Naceur, Y.Q. Guo, S. Ben-Elechi, Response surface methodology for design of sheet forming parameters to control springback effects, Comput. Struct. 84 (2006) 1651-1663

[14] H. Naceur, S. Ben-Elechi, J.L. Batoz, C. Knopf-Lenoir, Response surface methodology for the rapid design of aluminum sheet metal forming parameters, Mater. Des. 29 (2008) 781-790

[15] S. Sumikawa, A. Ishiwatari, J. Hiramoto, T. Urabe, Improvement of springback prediction accuracy using material model considering elastoplastic anisotropy and Bauschinger effect, J. Mater. Process. Technol. 230 (2016) 1-7

[16] M. Elbah, H. Aouici, I. Meddour, L. Boulanouar, Application of response surface methodology in describing the performance of mixed ceramic tool when turning AISI 4140 steel, Mech. Ind. 17 (2016) 309

[17] X. Wei, S.A. Asgari, J.T. Wang, B.F. Rolfe, H.C. Zhu, P.D. Hodgson, Micromechanical modelling of bending under tension forming behavior of dual phase steel 600, Comput. Mater. Sci. 108 (2015) 72-79

[18] K. Maji, D.K. Pratihar, A.K. Nath, Experimental investigations and statistical analysis of pulsed laser bending of AISI 304 stainless steel sheet, Opt. Laser. Technol. 49 (2013) 18-27

[19] H.R. Zarei, M. Kröger, Bending behavior of empty and foamfilled beams: Structural optimization, Int. J. Impact Eng. 35 (2008) 521-529

[20] R. Srinivasan, D. Vasudevan, P. Padmanabhan, Application of response surface methodology for predicting springback in air bending of electrogalvanised steel sheets, Int. J. Mat. Eng. Innov. 4 (2013) 35-56 
[21] W. Hu, L. Enying, L.G. Yao, Optimization of draw bead design in sheet metal forming based on intelligent sampling by using response surface methodology, J. Mater. Process. Technol. 206 (2008) 45-55

[22] M. Khelifa, K. Saanouni, Damage prediction in the deep drawing of thin sheets, Mech. Ind. 7 (2006) 465-473

[23] G. Sun, G. Li, Z. Gong, X. Cui, X. Yang, Q. Li, Multiobjective robust optimization method for drawbead design in sheet metal forming, Mater. Des. 31 (2010) 1917-1929

[24] M. Ozdemir, H. Gokmese, V. Yilmaz, H. Dilipak, Characterization of microstructure and bending response of sheet material, J. Adv. Mat. Process. 3 (2015) 3-14

[25] X. Liu, S. Zhao, Y. Qin, J. Zhao, W. A. Wan-Nawang, A parametric study on the bending accuracy in micro bending using Taguchi method, Measurement 100 (2016) 233-242

[26] R. Bahloul, S. Ben Elechi, A. Potiron, Optimisation of springback predicted by experimental and numerical approach by using response surface methodology, J. Mater. Process. Technol. 173 (2006) 101-110
[27] I. Karagac, The experimental investigation of springback in $V$-bending using the flex forming process, Arab. J. Sci. Eng. 42 (2017) 1853-1864

[28] H. Fathi, H.R. Mohammadian, E. Emadoddin, B. Mohammad Sadeghi, Effect of martensitic transformation on springback behavior of 304L austenitic stainless steel, Mater. Res. Express 4 (2017) 24-35

[29] B. Saidi, A. Boulila, M. Ayadi, R. Nasri, Experimental force measurements in single point incremental sheet forming SPIF, Mech. Ind. 16 (2015) 410

[30] D.K. Leu, Z.W. Zhuang, Springback prediction of the $V$-bending process for high-strength steel sheets, J. Mech. Sci. Technol. 30 (2016) 1077-1084

[31] K.A. Afimiwala, R.W. Mayne, A contour plotting scheme for design optimization, J. Mech. Des. 101 (1979) 349-354

[32] K.T. Chiang, C.C. Chou, N.M. Liu, Application of response surface m ethodology in describing the thermal performances of a pin type heat sink, Int. J. Therm. Sci. 48 (2009) 11961205

Cite this article as: D. Pritima, P. Padmanabhan, Investigation of sheet bending parameters on springback in nickel coated mild steel sheets using response surface methodology, Mechanics \& Industry 19, 206 (2018) 